University of Nebraska - Lincoln

DigitalCommons@University of Nebraska - Lincoln

2011

\title{
Multiple "hits" during postnatal and early adulthood periods disrupt the normal development of sensorimotor gating ability in rats
}

Jing Chen

Shanghai Jiao Tong University School of Medicine

Zucheng Wang

Shanghai Mental Health Center

Ming Li

University of Nebraska-Lincoln, mli2@unl.edu

Follow this and additional works at: https://digitalcommons.unl.edu/psychfacpub

Part of the Psychiatry and Psychology Commons

Chen, Jing; Wang, Zucheng; and Li, Ming, "Multiple "hits" during postnatal and early adulthood periods disrupt the normal development of sensorimotor gating ability in rats" (2011). Faculty Publications, Department of Psychology. 563.

https://digitalcommons.unl.edu/psychfacpub/563

This Article is brought to you for free and open access by the Psychology, Department of at DigitalCommons@University of Nebraska - Lincoln. It has been accepted for inclusion in Faculty Publications, Department of Psychology by an authorized administrator of DigitalCommons@University of Nebraska - Lincoln. 


\title{
Multiple "hits" during postnatal and early adulthood periods disrupt the normal development of sensorimotor gating ability in rats
}

\author{
Jing Chen, ${ }^{1,3}$ Zucheng Wang, ${ }^{2}$ and Ming $\mathrm{Li}^{3}$
}

1. Shanghai Jiao Tong University School of Medicine, 227 South Chongqing, Luwan District, Shanghai, P.R. China.

2. Shanghai Mental Health Center, 600 South Wanping, Xuhui District, Shanghai, P.R. China.

3. Department of Psychology, University of Nebraska-Lincoln, Lincoln, NE, USA.

Corresponding author - Professor Ming Li, 238 Burnett Hall, Department of Psychology, University of Nebraska-Lincoln, Lincoln, NE 68588-0308, USA. Email: mli2@unl.edu

\begin{abstract}
In the present study, we evaluated a multiple-hit animal model of schizophrenia in an attempt to capture the complex interactions among various adverse developmental factors in schizophrenia. Sprague-Dawley rats were assigned to receive either repeated daily 3-h maternal separation for eight days (first "hit") on postnatal days (PND) 3 to 10, and/or avoidance conditioning for six days (second "hit") on PND 49-56, and/or repeated phencyclidine treatment (third "hit", $3.0 \mathrm{mg} / \mathrm{kg}, \mathrm{sc}$ ) immediately after each daily avoidance conditioning. Prepulse inhibition (PPI) of acoustic startle reflex was assessed at late adolescence (PND 41-43) and early adulthood (PND 62-63). The change in \%PPI from the adolescence phase to adulthood phase was used to index the maturation-related improvement of sensorimotor gating ability. Maternal separation, avoidance conditioning, and PCP treatment had a complex three-way interaction on the functional improvement of sensorimotor gating. Maternal separation impaired PPI improvement preferentially in the saline rats that were not subjected to avoidance conditioning. Avoidance conditioning had no effect on PPI improvement in the non-maternally separated rats, but restored the maternal separation-induced disruption. However, this restoration effect was abolished by PCP treatment. The present study also identified a number of behavioral, emotional and learning abnormalities caused by these three developmental insults which may precede their interactive disruption of normal development of sensorimotor gating ability.
\end{abstract}

Keywords: animal models of schizophrenia, avoidance conditioning, maternal separation, phencyclidine, prepulse inhibition, pup vocalization, stress

\section{Introduction}

Schizophrenia is one of the most disabling illnesses (Lewis and Lieberman, 2000). It strikes individuals with susceptible genes in their late adolescence and early adulthood period, and is usually "triggered" by psychosocial and environmental stress during the postpubertal developmental period (Corcoran et al., 2001; Duncan et al., 1999). This neurodevelopmental view of schizophrenia emphasizes the contributions from various environmental insults along the neurodevelopmental trajectory for the increased risk of developing schizophrenia. Such insults may include intrauterine starvation or viral infections, perinatal complications, impaired maternal care and various non-specific social stressors (Anglin et al., 2008; Marenco and Weinberger, 2000; Weinberger, 1996).

Animal models play an important role in understanding the neurobiological mechanisms underlying the symptom development of schizophrenia (Kilts, 2001). One commonly adopted approach relies on the use of psychotomimetic drugs such as amphetamine or phencyclidine (PCP) or brain lesions to induce behavioral or neurochemical changes in adults ( $\mathrm{Li}$ et al., 2009a; Robinson and Becker, 1986). However, by design, they are incapable of capturing the developmental aspects of schizophrenia. Animal models focusing on the developmental risk factors have employed a variety of different approaches. Some of the well-known models include the neonatal ventral hippocampal lesion model (Le Pen et al., 2003; Lipska and Weinberger, 2002; Tseng et al., 2009), the maternal deprivation model (Ellenbroek et al., 1998), the postweaning social isolation rearing model (Wilkinson et al., 1994), the repeated preweaning maternal separation (MS) model (Weiss et al., 2001), and the perinatal repeated PCP treatment model (Andersen and Pouzet, 2004; Wang et al., 2001). Most studies report behavioral and biochemical changes bearing close resemblance to those observed in patients with schizophrenia, such as disrupted prepulse inhibition (PPI) of the acoustic startle reflex and latent inhibition, reduced social interaction and reward responding, impaired executive functioning, impaired visual attentional processes and enhanced sensitivity to stress (e.g. novel), dopamine agonists (e.g. apomorphine or amphetamine) and glutamate antagonists (e.g. PCP or MK-801). One attractive feature of these developmental models is their 
ability to mimic the delayed onset of psychotic symptoms in schizophrenia, as most of these behavioral and brain abnormalities found in animals do not emerge until after puberty. However, one limitation of these models is that they often employ one single developmental insult (i.e. "hit"), while schizophrenia is thought to be caused by multiple insults at different developmental periods critical to the brain structural and functional maturation (Pantelis et al., 2003), and a single insult is often not sufficient to cause schizophrenia.

Recently, Choy, van den Buuse and colleagues reported a two-hit animal model that comprises of a combination of an early first hit in the form of 24-h maternal deprivation on postnatal day (PND) 9, and a late second hit simulated by two weeks of corticosterone administration from eight to 10 weeks of age in rats (Choy et al., 2008, 2009; Choy and van den Buuse, 2008). They found that rats subjected to both manipulations showed a diminished disruption of PPI by apomorphine and amphetamine, suggesting a change in dopaminergic regulation of PPI. Inspired by this approach, in the present study, we examined a multiple-hit animal model in an attempt to capture the complex interactions among various adverse developmental factors in schizophrenia. We exposed rats to three distinct developmental insults (i.e. repeated MS, avoidance conditioning and PCP treatment) during the early postnatal period and early adulthood period and assessed PPI at both adolescence and adulthood phases, along with other behavioral measures such as pup ultrasonic vocalization, locomotor activity and defecation, and acquisition and maintenance of an instrumental response. Our results demonstrate that an early stressful life event (i.e. MS), coupled with late emotional stress (i.e. shock-induced avoidance responding) and a disruption on the glutamatergic systems (i.e. repeated PCP treatment) can have a negative impact on the normal development of sensorimotor gating ability in rats as they mature from adolescents to adults. This result is qualitatively similar to the PPI disturbance seen in patients with schizophrenia (Braff et al., 2001; Swerdlow et al., 2008), suggesting that employment of a neurodevelopmental model of this kind may be a profitable approach to delineate the mechanisms underlying the effects of various risk factors on the brain and behavior development that are relevant to schizophrenia.

\section{Materials and methods}

\section{Animals}

Ten untimed Sprague-Dawley pregnant female rats (912 weeks old at the start of pregnancy) were purchased from Charles River Inc. (Portage, MI). Upon arrival at our animal facility, the rats were between gestational days 13 and 15 . They were housed singly in $48.3 \mathrm{~cm} \mathrm{~L} \times 26.7 \mathrm{~cm} \mathrm{~W} \times 20.3 \mathrm{~cm} \mathrm{H}$ transparent polycarbonate cages lined with aspen shavings in a colony on a 12-hour light-dark cycle (lights on at 06:30). The humidity-controlled colony was maintained at approximately $22 \pm 1^{\circ} \mathrm{C}$. Starting one or two days before the first possible expected parturition date (day 22-23 gestation), the pregnant females were monitored every morning for signs of parturition. Once the dams were found with pups in the morning (the day designated postnatal day 1, PND 1), each litter was culled to
8 pups (4-5 males and 4-5 females with the most visible milk bands). A total of 80 pups were predetermined to be randomly assigned into eight treatment conditions (groups) on the basis of three "hit" factors that they would eventually be subjected to: MS, avoidance conditioning, and PCP treatment (a $2 \times 2 \times$ 2 complete factorial design, see Figure 1). Thus, each treatment group consisted of 10 rats from 10 different litters. The dams and their litters were housed together for 22 days, after which the pups were weaned from their mothers and housed four per cage (same-sex littermates) until PND 44, after which they were housed in same-sex pairs for the remainder of the experiment. All animal procedures were conducted in accordance to the National Institutes of Health Guide for the Care and Use of Laboratory Animals, and approved by the University of $\mathrm{Ne}$ braska Institutional Animal Care and Use Committee. The basic experimental design and testing procedure are illustrated in Figure 1.

\section{Maternal separation (i.e. first hit) PND 3-10}

Pups from five randomly chosen litters $(n=40)$ were assigned to the MS condition, while the remainder were assigned to non-MS condition. MS was chosen as the first insult because it is one of the most potent stressors for pups, as it activates the pups' stress response systems (Lupien et al., 2009), but does not by itself produce a long-lasting disruption on PPI (Lehmann et al., 2000b; Millstein et al., 2006; Weiss et al., 2001). Thus, it is a suitable first "hit" for the development of a multiple-hit model (i.e. avoiding a ceiling effect). MS was carried out daily from PND 3 to 10 using a widely used procedure (Francis et al., 2002; Rees et al., 2006). Litters were removed as a group and placed individually into one of eight small compartments $(12 \mathrm{~cm} \mathrm{~W} \times 15 \mathrm{~cm} \mathrm{H} \times 11 \mathrm{~cm} \mathrm{~L})$ in a transparent polycarbonate cage $(48.3 \mathrm{~cm} \times 26.7 \mathrm{~cm} \times 20.3 \mathrm{~cm})$ lined with bedding. Thus, each pup was also deprived from stimulations from littermates. The cage was maintained at nest temperature (approximately $34-35^{\circ} \mathrm{C}$ ) through the use of heating pads placed underneath the cage. After the $180 \mathrm{~min}(3 \mathrm{~h})$ separation and isolation period, pups were returned to the nest site and the dam was returned. The non-MS pups remained with their mothers in the home cages. To control for potential litter effects, an entire litter received the same treatment.

\section{Pup ultrasonic vocalization recordings on PND 14-15}

Rat pups emit ultrasonic vocalizations (USVs) centered around $40 \mathrm{kHz}$ in response to isolation from dams. This type of USV is regarded as a validated measure of anxiety/distress in infant rats (Iijima and Chaki, 2005). To examine whether MS affected isolation-induced USV and "maternal potentiation" of pup vocalization (Shair, 2007), we tested pup USV on PND 1415 (4-5 days after the MS period). Rat pups were first habituated to the testing environment three times on PND 3, 6, and 10. Each habituation consisted of placing individual pups in a plastic bowl-shape container $(14.5$ and $9.0 \mathrm{~cm}$ wide at the top and bottom, $7.5 \mathrm{~cm}$ high) situated in the middle of a two-compartment chamber $(64 \mathrm{~cm} \mathrm{~W} \times 30 \mathrm{~cm} \mathrm{H} \times 24 \mathrm{~cm} \mathrm{D})$ housed in a ventilated, sound-insulated isolation cubicle $(96.52 \mathrm{~cm} \mathrm{~W} \times$ $35.56 \mathrm{~cm} \mathrm{D} \times 63.5 \mathrm{~cm} \mathrm{H}$, Med Associates, St Albans, VT) for two minutes. On the USV test day (PND 14-15), rat pups were 

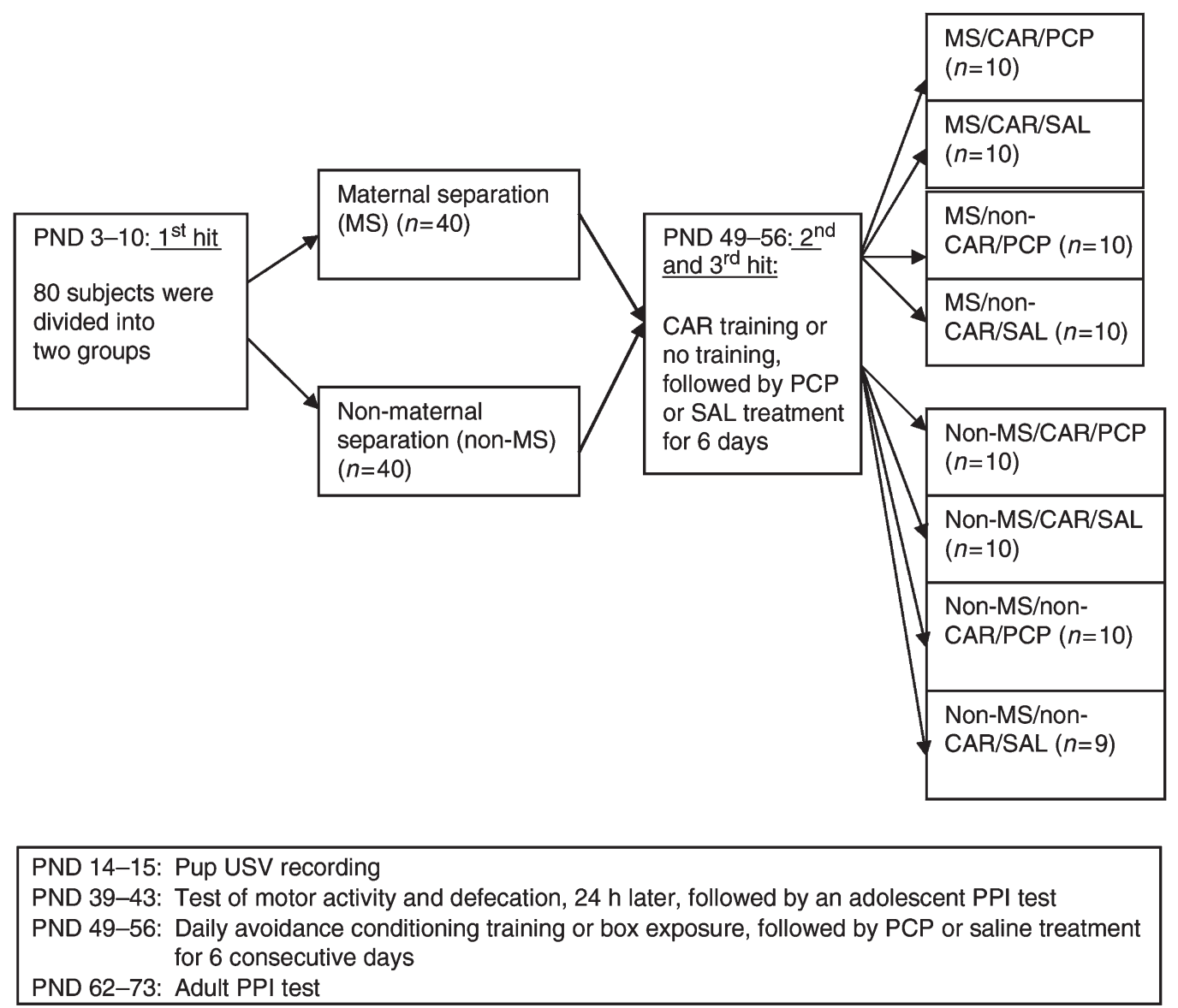

Figure 1. Schematics of the basic experimental design and testing schedule.

removed from their mothers and immediately placed in the bowl in the testing chamber for two minutes. Pup USV was recorded by an ultrasonic vocalization microphone (P48 Avisoft Bioacoustics/Emkay Microphone, Avisoft Bioacoustics, Berlin, Germany) mounted on the ceiling of the chamber. The microphone was connected via E-MU 0404 USB Audio device to a computer. Acoustic data were displayed in real time by the Avisoft RECORDER, a multi-channel triggering hard-disk recording software (version 3.4; Avisoft Bioacoustics), and were recorded at a sampling rate of $192 \mathrm{kHz}$ in 16-bit format and analyzed by Avisoft SASLab Pro (version 4.51; Avisoft Bioacoustics) with the lower cut-off frequency set at $23 \mathrm{kHz}$. After the initial 2-minute isolation/testing period (ISO1), pups were returned to their mothers for five minutes, after which they were tested again for another two minutes (ISO2). All of the tests were conducted between 09:00 and 12:00 and at room temperature $\left(22-24{ }^{\circ} \mathrm{C}\right)$. By the end of the postnatal period, one female pup from the non-MS group died unexpectedly. The following tests were conducted on the remaining 79 rats.

\section{Motor activity and defecation on PND 39-41}

On one day between PND 39 and 41, we assessed the spontaneous motor activity of the adolescent subject rats and re- corded the amount of defecation made by these subjects in a novel testing apparatus. Without any pretest handling and habituation to the testing apparatus, each subject was individually placed into one of 16 transparent polycarbonate cages $(48.3 \mathrm{~cm} \mathrm{~L} \times 26.7 \mathrm{~cm} \mathrm{~W} \times 20.3 \mathrm{~cm} \mathrm{H})$ equipped with a row of 16 photocell beams ( $2.5 \mathrm{~cm}$ between two adjacent photobeams) for 30 minutes. A computer detected the disruption of the photocell beams and recorded the number of beam breaks. At the end of testing, fecal matter was collected and weighed on a Mettler Toledo scale $(<0.1 \mathrm{mg})$.

\section{Conditioned avoidance training and repeated PCP treatment on PND 49-56}

Between PND 49 and 56, the subjects at their early adult phase were exposed to six days of conditioned avoidance training (CAR) or merely exposed to the CAR boxes (nonCAR). Immediately after the completion of the daily CAR or box exposure session, rats were taken out from the boxes and injected with PCP (3.0 mg/kg, sc, Sigma-Aldrich, St Louis, $\mathrm{MO})$ or saline, and returned to their home cages afterwards. CAR served as the second "hit" as it causes physical and psychological stress (Li et al., 2004; Mowrer and Lamoreaux, 1946). As CAR is also an instrumental learning task (Rescorla 
and Solomon, 1967), it provides an opportunity to assess how early MS and PCP affected learning and memory. PCP has been widely used to create animal models of schizophrenia (Javitt and Zukin, 1991; Li et al., 2009a; Sun et al., 2009). Previous work has shown that repeated PCP treatment during the postnatal or postweaning period disrupts the functions of glutamatergic systems and causes learning and memory deficits (Andersen and Pouzet, 2004; Schwabe et al., 2006; Wang et al., 2001), thus it was employed here as the third "hit". For the CAR rats, they were trained daily in a modified two-way avoidance conditioning task for six consecutive days. The training apparatus consisted of eight identical two-compartment chambers used in the pup USV recording (Li et al., 2008, 2009a). Each chamber was divided into two equal-sized compartments by a white PVC partition with an arch style doorway (15 cm high $\times 9 \mathrm{~cm}$ wide at the base). An aluminum hurdle (4 cm high) was placed between the two compartments, so the rats had to jump from one compartment to the other. The grid floor consisted of 40 stainless steel rods with a diameter of $0.48 \mathrm{~cm}$, spaced $1.6 \mathrm{~cm}$ apart center to center, through which a scrambled footshock (US, $0.8 \mathrm{~mA}$ ) was delivered by a constant current shock generator (Model ENV-410B) and scrambler (Model ENV-412). The rat location and motor activity was detected by a set of 16 photobeams (ENV-256-8P) affixed at the bottom of the box ( $3.5 \mathrm{~cm}$ above the grid floor). One houselight $(28 \mathrm{~V})$ mounted at the top of each compartment. Each training session consisted of 30 trials and lasted about 30 minutes (Li et al., 2009a). Fourteen trials (CS1 trials) used a 10 s 76 $\mathrm{dB}$ white noise as the CS that was always followed by the US shock if the rats did not make an avoidance response; thus, it was a highly salient and perfect predictor of the US. The remaining 16 trials (CS2 trials) used a pure tone $(10 \mathrm{~s}, 2800 \mathrm{kHz}$, $85 \mathrm{~dB}$ ) as the CS. In half of the CS2 trials (eight trials), the CS2 was followed by the shock; in the other half, it was not; thus, it was a less-salient and less-informative signal compared with CS1. The 14 CS1 trials were randomly intermixed with the 16 CS2 trials. During each trial, if a subject moved from one compartment into the other within the 10 seconds of CS presentation, the CS was terminated and the shock was prevented, and this shuttling response was recorded as avoidance (termed CS1 avoidance or CS2 avoidance). If the rat remained in the same compartment for more than $10 \mathrm{~s}$ and made a crossing upon receiving the footshock, this response was recorded as an escape. If the rat did not respond during the entire $5 \mathrm{~s}$ presentation of the shock, the trial was terminated and escape failure was recorded. All of the procedures were controlled by Med Associates programs running on a computer. Background noise (approximately $74 \mathrm{~dB}$ ) was provided by a ventilation fan affixed at the top corner of each isolation cubicle. Non-CAR rats were merely exposed to the testing apparatus for 30 minutes. Their motor activity and amount of defecation in the boxes were recorded.

\section{PPI tests during adolescence and adulthood}

PPI was assessed at two developmental periods. The first PPI test was conducted during the adolescence period (one day between PND 41 and 43) (Spear, 2000), and the second PPI test was conducted during the early adult period (one day be- tween PND 62 and 63). The basic PPI procedure was identical in each testing phase. Six startle monitor systems (Kinder Scientific, Julian, CA), controlled by a PC, were used as the testing apparatus. They were housed in compact sound attenuation cabinets $(35.56 \mathrm{~cm}$ wide $\times 27.62 \mathrm{~cm}$ deep $\times 49.53 \mathrm{~cm}$ high). A speaker (diameter $11 \mathrm{~cm}$ ) mounted on the cabinet's ceiling was used to generate acoustic stimuli (70-120 dB). The startle activity was measured by a piezoelectric sensing platform on the floor. At the beginning of the test, rats were placed in a rectangular plastic box with adjustable ceiling (adjusted lower for adolescent rats). The testing session lasted approximately 18 minutes and began with a 5-minute period of $70 \mathrm{~dB}$ background noise (which continued throughout the duration of the session) followed by four different trial types: PULSE ALONE trials and three types of PREPULSE $\times$ PULSE trials, which consisted of a $20 \mathrm{~ms} 73,76$, or $82 \mathrm{~dB}$ prepulse $(3,6$, and $12 \mathrm{~dB}$ above background) followed $100 \mathrm{~ms}$ later by a $120 \mathrm{~dB}$ pulse. Each session was divided into four blocks. Blocks 1 and 4 were identical, each consisting of four PULSE ALONE trials. Blocks 2 and 3 were also identical and consisted of eight PULSE ALONE trials and five of each PREPULSE $\times$ PULSE trial type. A total of 54 trials were presented during each testing session. Trials within each block were presented in a pseudorandom order and were separated by a variable intertrial interval averaging 15 seconds (ranging from 9-21 seconds). Whole body startle responses were recorded in Newtons, and responses from testing blocks 2 and 3 were used to calculate \%PPI using the following equation:

\section{$100-[($ mean prepulse response/mean pulse response $) \times 100]$}

a higher \%PPI implies greater inhibition of startle response due to presentation of the prepulse signals.

\section{Statistical analysis}

The adolescent motor activity and defecation data were analyzed using a factorial analysis of variance (ANOVA) with the MS (MS versus non-MS) and sex (male versus female) as two between-subjects factors. Pup USV data were analyzed in the same way with an additional within-subjects factor being the test sessions (ISO1 versus ISO2). To examine the influence of early MS and repeated PCP treatment on the acquisition and maintenance of avoidance responding, we analyzed the CS1 and CS2 avoidances using a repeated measures ANOVA with the MS (MS versus non-MS) and drug treatment (PCP versus saline) as two between-subjects factors and the test days and types of trials (CS1 versus CS2 avoidance) as the within-subject factors. To examine the influence of early MS and repeated PCP treatment on motor activity and defecations in the non-CAR rats, we used either a univariate ANOVA test (for day 1) or a repeated measures ANOVA test (for days 2-6). Finally, adolescent PPI and adult PPI data as well as the \%PPI change data $(\%$ PPI change $=$ adult $\%$ PPI - adolescent $\%$ PPI $)$ were analyzed using a repeated measures ANOVA with MS, CAR training, and drug treatment as three between-subjects factors. The within-subject factor was the PPI (73, 76, and 82 $\mathrm{dB})$. As we did not monitor the estrous cycle of female adult rats when they were tested in the CAR and PPI, we thus did not examine the effect of sex on these measures. 


\section{Results}

\section{Effects of MS from PND 3-10 on pup USV, spontane- ous motor activity and defecations in PND 39-41 ad- olescent rats}

Isolation-induced pup USV and re-isolation-induced potentiation of pup USV has been used as an ecologically relevant measure of distress in infant rodents (Olivier et al., 1998). To examine whether MS affected isolation-induced USV and "maternal potentiation" of pup vocalization (Shair, 2007), we compared the number of pup USV between the MS $(n=40)$ and non-MS groups $(n=40)$. Our analysis revealed a significant main effect of test sessions $(F(1,76)=16.152, p<0.001)$, $\operatorname{sex}(F(1,76)=4.329, p=0.041)$, but no main effect of MS ( $F(1$, 76) $=0.061, p=0.806)$, nor any interaction among these factors (all $p>0.05$ ). In general, after a brief (five minutes) reunion with the dams, rat pups made more vocalization calls at the re-isolation test point (ISO2) than at the initial isolation test point (ISO1) (Figure 2A), confirming the maternal potentiation of pup USV (Muller et al., 2005; Shair, 2007). Male pups tended to make more USV calls than females at both testing points (Figure 2B).

To examine how MS might have affected spontaneous motor activity and anxiety in adolescent rats, motor activity and defecation were recorded in a 30-minute test on one day between PND 39 and 41. The maternal separated $(n=40$; male:female $=21: 19)$ and non-separated $(n=39$; male: female $=20: 19)$ adolescent rats were compared. We found that female rats were more active than males (a main effect of sex: $F(1,75)$ $=4.639, p=0.034$, data not shown), consistent with the known sex difference in activity (Chapman and Stern, 1979; Lehmann et al., 2000b). Early MS slightly increased the level of motor activity, but this effect was marginally significant $(F(1,75)=$ $3.660, p=0.06$, Figure 3A). More interestingly, MS significantly increased the amount of defecations (a main effect of MS: $F(1$, $75)=4.10, p=0.046$, Figure 3B). There was also a significant main effect of $\operatorname{sex}(F(1,75)=6.245, p=0.015$, Figure 3C), but no significant MS $\times$ sex interaction $(F(1,75)=3.285, p=0.074)$. Because defecation is regarded as a sensitive measure of fear/ anxiety (Antoniadis and McDonald, 1999; Mead et al., 2008), our finding suggests that postnatal MS increased novelty-induced fear/anxiety in adolescent rats.

\section{Effects of MS and PCP treatment on the acquisition of avoidance responding in the CAR rats}

During the CAR training and PCP treatment phase (PND $49-56), 40$ rats (20 from the MS group and 20 from the nonMS group) were subjected to six days of CAR training and repeated PCP ( $n=20$ : $10 \mathrm{MS}$ and 10 non-MS rats) or saline treatment ( $n=20,10 \mathrm{MS}$ and 10 non-MS rats). Throughout the six training sessions, all rats showed a progressive increase in the number of CS1 and CS2 avoidance responses across sessions (Figure 4A-D). It appears that rats acquired CS1 avoidance faster, and made more avoidance responses to CS1 than to CS2, a result that was expected from the experimental design in which only half of the CS2 trials were followed by footshock, whereas all of the CS1 trials were followed by shock if the rats failed to respond. Repeated measures ANOVA with MS and PCP as two between-subjects factors and the test days and types of trials (CS1 versus CS2 avoidance) as the within-subject factors indicated a significant main effect of test sessions $(\mathrm{F}(5,180)=41.811, p<0.001)$, trial types $(\mathrm{F}(1,36)$ $=308.555, p<0.001)$, and the interaction between the two $(F(5$, $180)=4.270, p=0.001)$, but no main effect of MS $(F(1,36)=$ $0.697, p=0.409)$, PCP treatment $(F(1,36)=0.327, p=0.571)$, nor the interaction between the two $(F(1,36)=2.58, p=0.117)$. However, there was a significant three-way interaction among the test sessions, MS and PCP treatment $(F(5,180)=3.198, p=$ 0.009 ), suggesting that PCP treatment differentially affected the acquisition of avoidance responding in the MS and nonMS rats throughout the training days. Inspection of Figure 4 suggests that PCP impaired the acquisition of avoidance responding in the MS rats, whereas it slightly increased acquisition in the non-MS rats.

\section{Effects of MS and PCP treatment on motor activity and defecations in the non-CAR rats}

For the non-CAR rats, 19 (10 MS and 9 non-MS rats) were treated with saline and 20 (10 MS and 10 non-MS rats) with PCP immediately after they were removed from the CAR boxes. As rats received PCP or saline injection after the exposure to the CAR boxes on each day, day 1 motor activity and defecation served as baseline measures for the effects of PCP treatment. The univariate ANOVA test did not find any significant effect of PCP treatment on day 1 motor activity $(F(1$, $37)=0.870, p=0.770)$ or day 1 defecation $(F(1,37)=0.793, p$ $=0.379$ ). Repeated measures ANOVA on the last 5 days indicated that PCP treatment significantly decreased motor activity $(F(1,35)=7.444, p=0.010)$ and increased amount of defecation $(F(1,35)=6.983, p=0.012)$ (Figure 5). The motor-depressive effect was stronger in the MS rats than in the non-MS rats as there was a significant three-way interaction among the days, MS and PCP treatment $(F(4,140)=3.052, p=$ $0.019)$. The PCP effect on defecation shows a progressive enhanced trend $(\mathrm{PCP} \times$ days interaction: $F(4,140)=2.730, p=$ 0.032 ). MS had little effect on any of these measures (day 1 motor activity: $F(1,37)=0.583, p=0.450$; day 1 defecations: $F(1,37)=0.018, p=0.894$; days $2-6$ motor activity: $F(1,35)$ $=0.188, p=0.667$; days $2-6$ defecations: $F(1,35)=0.185, p=$ $0.670)$. As drug-induced motor suppression and increase in amount of defecation are indicators of anxiety/fear (Li et al., 2009b), this finding suggests that repeated PCP treatment facilitated anxiety/fear development, and this anxiogenic effect was potentiated by early MS.

\section{Effects of MS, avoidance conditioning and PCP treat- ment on PPI in adolescent and adult rats}

Early MS did not affect PPI in adolescent rats (Figure $6 \mathrm{~A}$ ) or the basal startle magnitude to the $120 \mathrm{~dB}$ pulse (data not shown, $F(1,77)=0.128, p=0.722$ ). Repeated measures ANOVA with MS as a between-subject factor and the PPIs as a within-subject factor showed that there was a significant effect of PPIs $(F(2,154)=141.201, p<0.001)$, but no significant ef- 


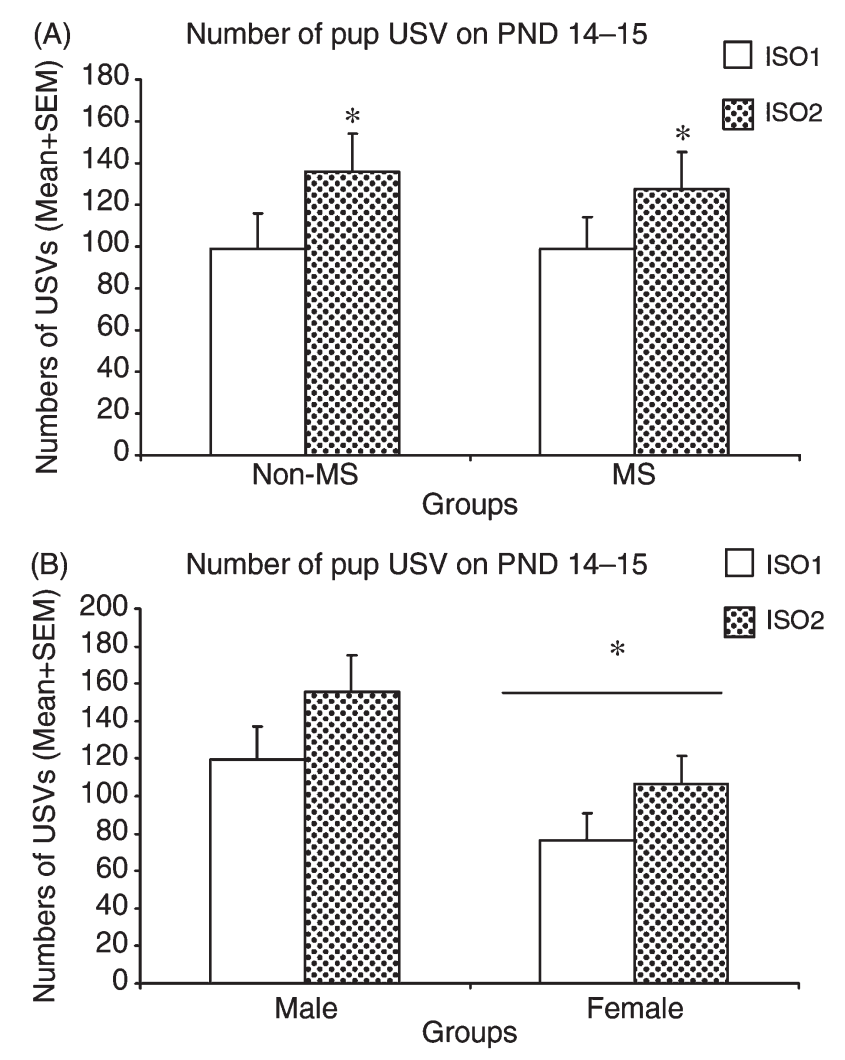

Figure 2. Isolation and re-isolation-induced pup ultrasonic vocalizations (USVs) recorded on postnatal days (PND) 14-15. After the initial 2-minute isolation/testing period (ISO1), pups that had experienced repeated daily maternal separation (MS) from PND 3 to 10 ( $\boldsymbol{n}=40$ ) or not experienced such a separation $(\boldsymbol{n}=40)$ were returned to their mothers for 5 minutes, after which they were tested again for another 2 minutes (ISO2). All of the tests were conducted at room temperature (22-24_C). Data are presented as mean \pm SEM. Pup USVs are presented on the basis of early MS condition $(A)$ or sex $(B) .{ }^{*} \boldsymbol{p}<0.05$ for significant group difference.

fect of $\operatorname{MS}(F(1,77)=1.234, p=0.270)$, nor any interaction between the two $(F(2,154)=1.775, p=0.173)$. Male and female rats exhibited a similar pattern of PPI as factoring in sex into in the repeated measures ANOVA did not reveal any significant effect associated with this factor (all $p>0.05$ ).

To examine the long-term effects of MS, avoidance conditioning, and repeated PCP treatment on rat's sensorimotor gating ability, we assessed PPI in adult rats on PND 62-63. None of the three factors had a significant effect on the absolute \%PPI at the three intensity levels or the basal startle magnitude to the $120 \mathrm{~dB}$ pulse, nor did they show any significant interaction on these measures (see Figure 6B, all $p>0.05$ ). As there were large individual differences in the adolescent PPI (see Figure 6C), in order to better account for this baseline difference and reveal the true impact of MS, CAR, and repeated PCP treatment on the adult PPI, we calculated each rat's \%PPI change (three levels) from adolescence to adulthood (adult $\%$ PPI - adolescence \%PPI) as the main dependent variable. This \%PPI difference measurement used each subject as its own control, thus accounting for the individual differences better. Repeated measures ANOVA on this measurement showed a significant three-way interaction among MS, CAR and PCP treatment $(F(1,71)=6.517, p=0.013)$ and a significant interaction among PPIs, MS and $\operatorname{CAR}(F(2,142)=3.112$, $p=0.048)$, suggesting that these three developmental insults ("hits") interacted in a complex way in changing PPI improve- ment, and their interaction was dependent on the PPI. Inspection of Figure 6D suggests two possible effects. First, MS had a disruptive effect on PPI improvement (\%PPI change from adolescence to adulthood) preferentially in the SAL and non-CAR rats. Independent-samples $t$-tests comparing the non-MS/ non-CAR/SAL group with MS/non-CAR/ SAL group confirmed this observation $(t(17)=2.120-2.298, p=0.035-0.049)$. Second, CAR and PCP affected PPI improvement differently in the MS rats than in non-MS rats. CAR and PCP treatment had little effect on PPI improvement in the non-MS rats (no main effects of CAR: $F(1,35)=0.028, p=0.867$; PCP: $F(1,35)=$ $0.022, p=0.882$ or their interaction: $F(1,35)=0.582, p=0.451)$. However, in the MS rats, CAR restored PPI improvement that was disrupted by MS (a significant main effect of CAR: $F(1$, $36)=4.298, p=0.045)$, suggesting that CAR could alleviate the disruptive effect of MS. This observation was also supported by the significant group difference between the MS/CAR/ SAL and MS/non-CAR/SAL group (Figure 6D, $t(18)=2.591-$ $3.136, p=0.018-0.006)$. However, this restoration effect of CAR was abolished by PCP treatment (a significant CAR $\times$ PCP interaction, $F(1,36)=7.990, p=0.008)$. Independent-samples $t$ tests comparing the MS/CAR/SAL group with the MS/CAR/ PCP group confirmed this effect of PCP, as PPI improvement at the $76 \mathrm{~dB}$ and $82 \mathrm{~dB}$ levels were significantly lower in the MS/CAR/PCP group than in the MS/CAR/SAL group (76 $\mathrm{dB}: t(18)=2.225, p=0.039 ; 82 \mathrm{~dB}: t(18)=2.449, p=0.025)$. 
(A) Motor activity during the motor activity test on PND 39-41

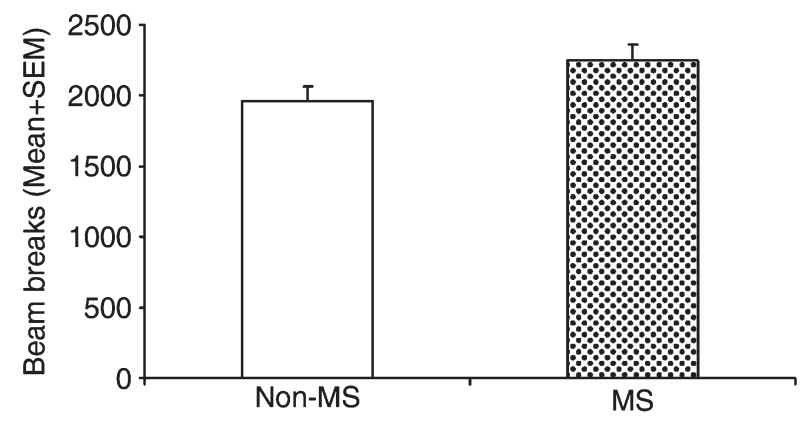

(B) Amount of defecation in the motor activity test on PND 39-41

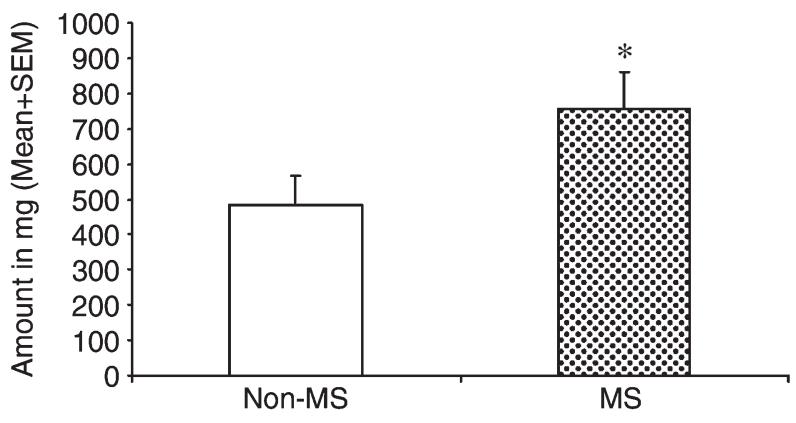

(C) Amount of defecation in male and female rats on PND 39-41

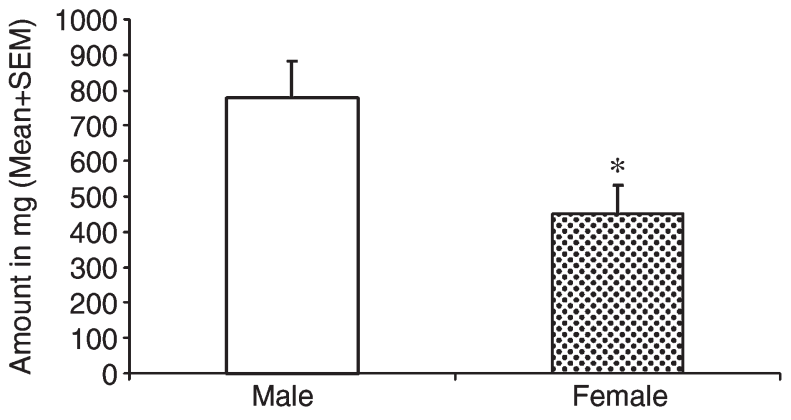

Figure 3. Locomotor activity (A) and amount of defecation during a 30-minute test on postnatal days (PND) 39-41. The maternal separated (MS, $\boldsymbol{n}=40 ;$ male:female $=21: 19$ ) and non-separated (non-MS, $\boldsymbol{n}=39$; male:female $=20: 19$ ) rats were compared. Data are expressed as mean \pm SEM. Defecation data are depicted on the basis of early MS condition (B) and sex (C). ${ }^{*} \boldsymbol{p}<0.05$ for significant group difference.

In terms of overall differences among the eight experimental groups, it appears that the MS/non-CAR/SAL group and the MS/CAR/PCP group had the worst PPI improvement, whereas the MS/CAR/SAL had the best. This finding is consistent with the impression that MS impaired PPI improvement, which was restored by avoidance training, but re-disrupted by PCP treatment.

\section{Discussion}

The present study was initiated on the basis of the "twohit" hypothesis of schizophrenia (Bayer et al., 1999; Maynard et al., 2001; Van den Buuse et al., 2003). According to this hypothesis, an early "hit" (e.g. predisposing genetic factors, early maternal stress) disrupts early central nervous system devel- opment and increases vulnerability to a "second hit" (e.g. drug abuse or social stress) which then leads to the onset of schizophrenia symptoms. In the present study, we simulated a "first hit" by a repeated early MS procedure and a "second hit" by repeated avoidance conditioning. In addition, PCP was used to disrupt the glutamatergic functions and mimic a functional impairment on the brain development (i.e. a "third hit"). We found that a combination of three adverse events during the critical developmental periods can cause a number of behavioral changes in rats that resemble several aspects of the symptoms of schizophrenia. Specifically, we found that repeated daily 3-h MS from PND 3 to 10 increased the novelty-induced anxiety/fear in adolescent rats and disrupted normal PPI development in adult rats, but did not affect separation-induced anxiety in infant rats as measured by pup USV. Early postnatal MS also potentiated the anxiogenic effect of PCP. Avoidance conditioning restored PPI improvement in the MS rats, 

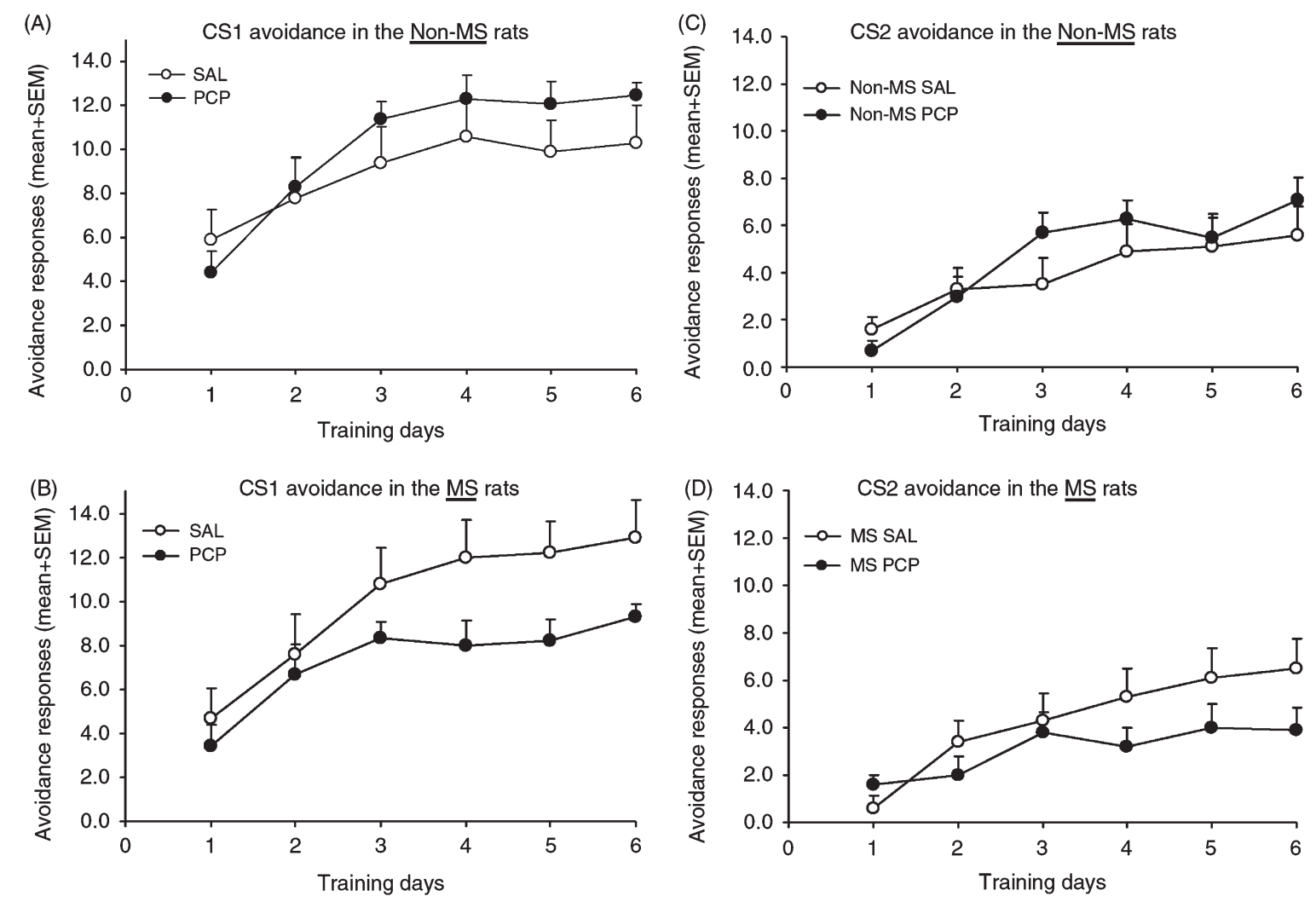

Figure 4. CS1 and CS2 avoidance responses throughout the six training days on postnatal days (PND) 49-56. Each point represents the mean number of avoidance responses \pm SEM. CS1 and CS2 avoidance responses are presented for the non-maternal separation (non-MS) rats $(\boldsymbol{n}=20, \mathrm{~A}, \mathrm{C})$ and MS rats $(\boldsymbol{n}=20, B, D)$ separately. After each daily conditioned avoidance training (CAR), rats were taken out from the chambers and immediately injected with $\mathrm{PCP}(3.0 \mathrm{mg} / \mathrm{kg}, \mathrm{sc})$ or saline $(\mathrm{SAL})$, and returned to their home cages afterwards.

but had little effect on PPI improvement in the non-separated rats. Repeated PCP treatment impaired avoidance learning, preferentially increased anxiety in the MS adult rats, and abolished the restoration by avoidance condition on PPI improvement. These findings demonstrate a complex interaction (not a simple additive effect) among the three distinct insults on the emotional responses, instrumental learning and normal development of sensorimotor gating ability from adolescence to adulthood. To the extent that these behavioral changes, especially the disruption of normal development of sensorimotor gating ability, reflect mental functional dysregulations seen in patients with schizophrenia, the present "multiple-hit" model may be particularly useful for the study of mechanisms responsible for the behavioral and neurobiological processes disrupted by schizophrenia.

In the present study, we found that adolescent rats who had experienced repeated daily $3-\mathrm{h}$ separation from mothers defecated more in a novel environment. We also found that PCP treatment preferentially increased defecation and decreased motor activity in the maternally separated rats, but not in the control rats. These data indicate an anxiogenic effect of early MS, which is consistent with most animal work showing that adult rats who have been reared in a MS condition tend to exhibit increased sensitivity to stress (Holmes et al., 2005; Liu et al., 2000; Rosenfeld et al., 1992) and increased anxiety or fear-like behavior (Huot et al., 2001; Rees et al., 2006; Wigger and Neumann, 1999). For example, Wigger and Neumann (1999) employed a similar MS procedure as ours and found enhanced anxiety in adult rats as measured by the elevated plus-maze test. These findings are also in agreement with well-documented clinical observations that childhood trauma and maternal neglect can increase risk for depression and anxiety disorders (Anda et al., 2006; Bifulco et al., 1991; Mackinnon et al., 1993). Given the fact that psychotic fear and anxiety disturbances are seen at a relatively high frequency in patients with schizophrenia (Siris, 1994), these findings suggest that one possible source of enhanced emotionality in schizophrenia is the disrupted early maternal and social environment, possibly the impaired quality of maternal care and abnormal stimulations from littermates (Ellenbroek and Cools, 2002). MS may increase anxiety or fear by causing functional and structural changes in the brain, most notably in the hypothalamic-pituitary-adrenal (HPA) axis, the hippocampus, and other limbic structures that are important for regulating stress and emotional responses (Cirulli et al., 2003).

Previous studies on the effects of repeated daily MS on PPI in adulthood have consistently reported a lack of disruptive effect (Lehmann et al., 2000b; Millstein et al., 2006; Weiss et al., 2001). Our finding that early MS did not disrupt absolute \%PPI (see Figure 6B) is consistent with this general observation. 

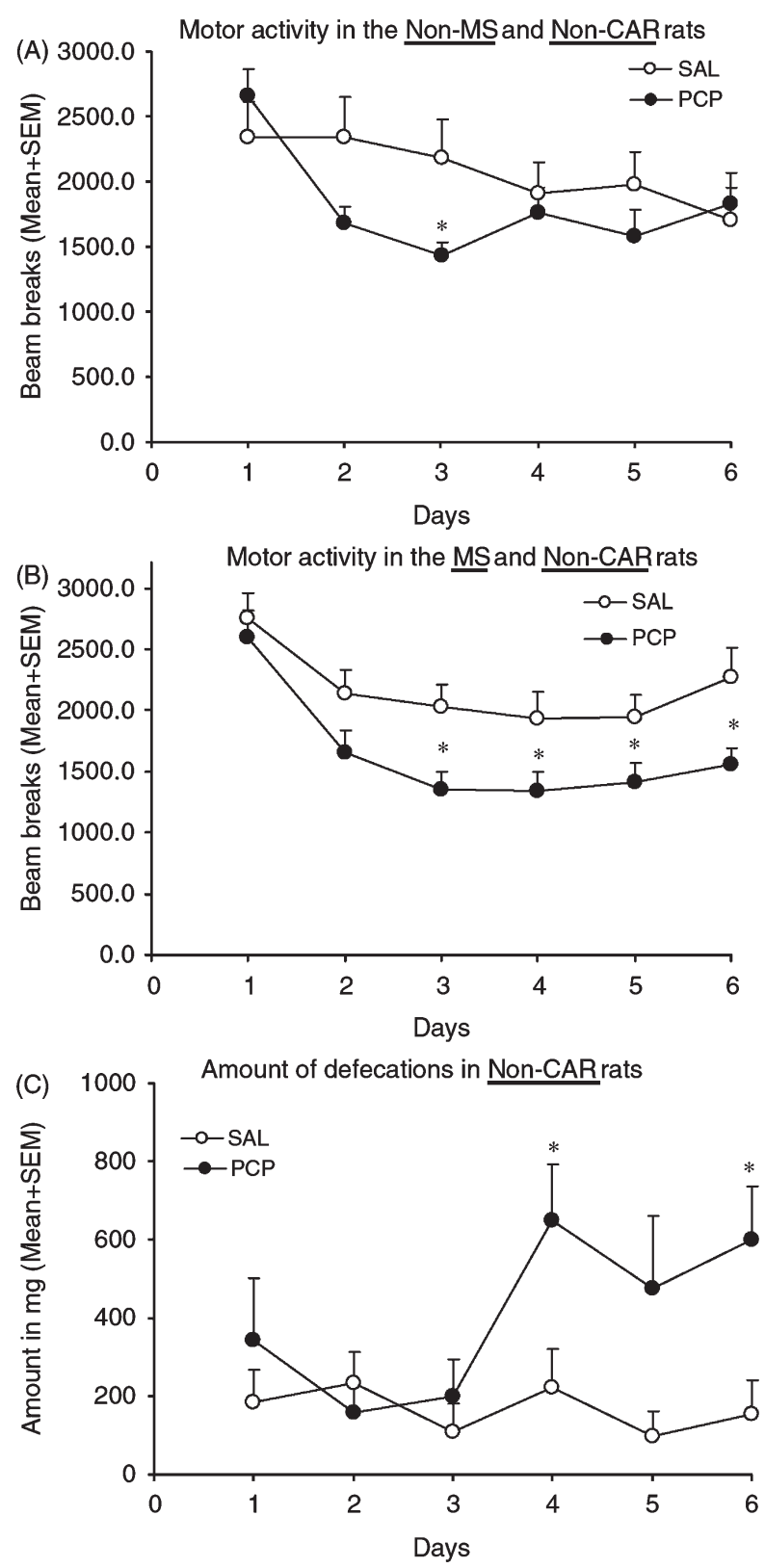

Figure 5. Locomotor activity (A, B) and amount of defecation (C) during the six daily motor activity tests on postnatal days (PND) 49-56. During each test, maternal separation (MS) and non-MS rats were exposed to the conditioned avoidance training (CAR) testing apparatus for 30 minutes. After each daily session, rats were taken out from the chambers and immediately injected with PCP $(3.0 \mathrm{mg} / \mathrm{kg}, \mathrm{SC}, \boldsymbol{n}=20)$ or saline $(\boldsymbol{n}=19)$ and returned to their home cages afterwards. ${ }^{*} \boldsymbol{p}<0.05$ for significant group difference.

Other forms of MS such as a single 24-h maternal deprivation on PND 9 have also generated mixed results (Choy and van den Buuse, 2008; Ellenbroek and Cools, 2002; Ellenbroek et al., 1998, 2004; Lehmann et al., 2000a). This lack of effect of early MS has prompted others to suggest that repeated daily MS for 1-6 $\mathrm{h}$ is not severe enough to alter the quality of maternal care and alter the trajectory of brain and behavior developments (Pryce et al., 2003). Weiss and Feldon (2001) also suggested that early MS does not represent a robust or reliable model of early life stress effects on sensorimotor gating deficits, as seen in schizophrenia. In the present study, we noticed that there were substantial individual differences in the adolescent (Figure 6C) and adult absolute \% PPI (data not shown), which could have decreased the likelihood of obtaining statistically significant effects. Thus, we calculated each rat's \%PPI changes from adolescence to adulthood and used these \%PPI differences as the main index of the maturationrelated improvement of rat sensorimotor gating ability. This approach used each rat as its own control, thus it accounts better for the baseline individual differences and provides a more sensitive measure of the impact of various developmental manipulations on the normal development of sensorimotor gating ability. We did not use "percentage change" in \%PPI from adolescence to adulthood because some rats (23 out of 79 adolescent rats) exhibited negative \%PPI, which makes this measurement unsuitable. Using this measurement, we did find that early MS significantly disrupted the normal PPI development preferentially in the saline rats that were not subjected to avoidance conditioning. This finding suggests that early repeated MS could have a profound and pervasive influence on the normal development of attentional processing. However, we should emphasize that this conclusion is based on the assumption that the \%PPI change from adolescence to adulthood reflects the maturation-related improvement of rat sensorimotor gating ability. To the best of our knowledge, no other PPI work has used such a measure. Thus, it is important for future work to specifically examine the psychological meaning of \%PPI change from adolescence to adulthood and determine the validity of such a measurement as an index of the natural development of attentional processing as an organism matures.

There have been relatively few studies examining the complex interactions among various environmental factors during the critical brain developmental periods on sensorimotor gating. Most work has only used two developmental manipulations. For example, Ellenbroek and Cools (2002) reported that either maternal deprivation (a single 24-h period on PND 9) or social isolation rearing after weaning disrupted PPI in adulthood. However, the combination of both manipulations did not cause a greater disruption but rather gave rise to normal PPI, suggesting that social isolation rearing reversed the effects of maternal deprivation on PPI. Lehmann et al. (2000b) investigated the consequences of the combination of prenatal stress and MS on PPI in adulthood. They found that prenatal restraint stress enhanced PPI, but this enhancing effect was normalized by MS. Choy and van den Buuse (2008) reported that the combination of 24-h maternal deprivation with 2-week corticosterone treatment attenuated the PPI-disruptive effect of acute apomorphine treatment to a greater extent than either maternal deprivation or corticosterone treatment alone. All of these findings suggest that the combination of different developmental factors does not necessarily result in the simple additive effects of the long-term PPI-disruptive effect of each manipulation. Our findings that avoidance conditioning restored MS-induced disruption on PPI improvement, and repeated PCP treatment abolished the improving effect of avoidance conditioning are, in principle, consistent with these observations, as they clearly indicate a complex 

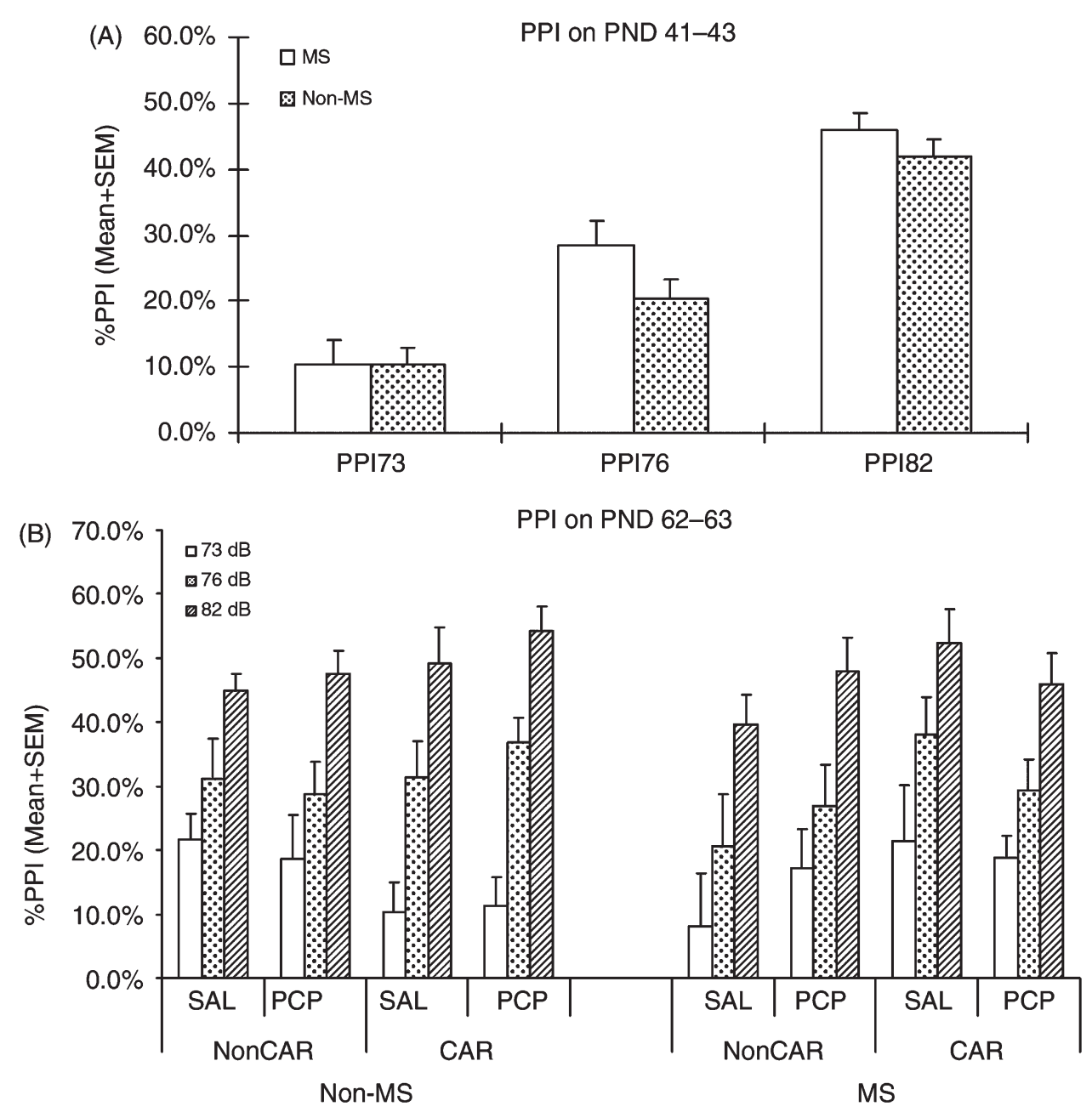

Figure 6. Prepulse inhibition of the startle response (calculated according to the formula described in the "Materials and methods" as a function of prepulse intensity (PPI; i.e. 73, 76 and $82 \mathrm{~dB}$ ) in the adolescent rats (A) and in the adult rats (B). Data are expressed as group mean \pm SEM. Individual \%PPI (averaged across the three PPIs) in the MS and non-MS adolescent rats (C) are depicted to show the range of individual differences. The group mean \%PPI changes from adolescence to adulthood (calculated according to the formula described in the "Materials and methods") (D) are also depicted. The three developmental insults ("hits") had a complex three-way interaction on PPI improvement. Each bar represents the group mean of 10 rats (except the non-MS/non-CAR/SAL, which had nine rats). ${ }^{*} \boldsymbol{p}<0.05$ for significant group difference between the non-MS/non-CAR/ SAL group and MS/Non-CAR/SAL group; ${ }^{\#} \boldsymbol{p}<0.05$ for significant difference between the MS/CAR/SAL group and MS/non-CAR/SAL group; ${ }^{\$} \boldsymbol{p}<$ 0.05 for significant group difference between the MS/CAR/SAL group and the MS/CAR/PCP group.

three-way interaction among early MS, avoidance conditioning and PCP treatment. Our multiple-hit model added another layer of complexity to the two-hit model in which we not only confirmed two manipulations can cancel each other out (i.e. CAR restored the MS effect), but also showed that a third manipulation can even reinstate the effect of the first (i.e. PCP reinstated the disruptive effect of MS). This unique feature associated with the three-hit approach may possess better clinical relevance than the two-hit approach, as most patients with schizophrenia often experience multiple sources of environmental insults that target different neural and endocrine systems (Carpenter and Buchanan, 1994). Our finding that different groups of rats that had been subjected to different combinations of multiple "hits" (e.g. the MS/non-CAR/ SAL and the MS/CAR/ PCP group) exhibited similarly disrupted PPI improvement may also provide a clue to the causes of different phenotypes of schizophrenia as observed in the clinic. We speculate that this phenomenon is likely due to the fact that each patient has experienced different combinations of environmental insults at different developmental periods.

In the present study, we conducted MS on PND 3-10 because it has been suggested that the first 2-week postnatal period of a rat corresponds to the second trimester of pregnancy (Fitzgerald and Anand, 1993), which is the critical period of fetal central nervous system development sensitive to viral or environmental insult (Machon et al., 1987; Mednick et al., 1988; Sullivan et al., 2006). Thus, MS during this period is likely to cause a disruption of early central nervous system development and increase vulnerability to a "second hit" (e.g. stress and psychotomimetic drug) (Sullivan et al., 2006). We chose to impose stress and PCP treatment on PND 49-56 because this period corresponds to human puberty and early 


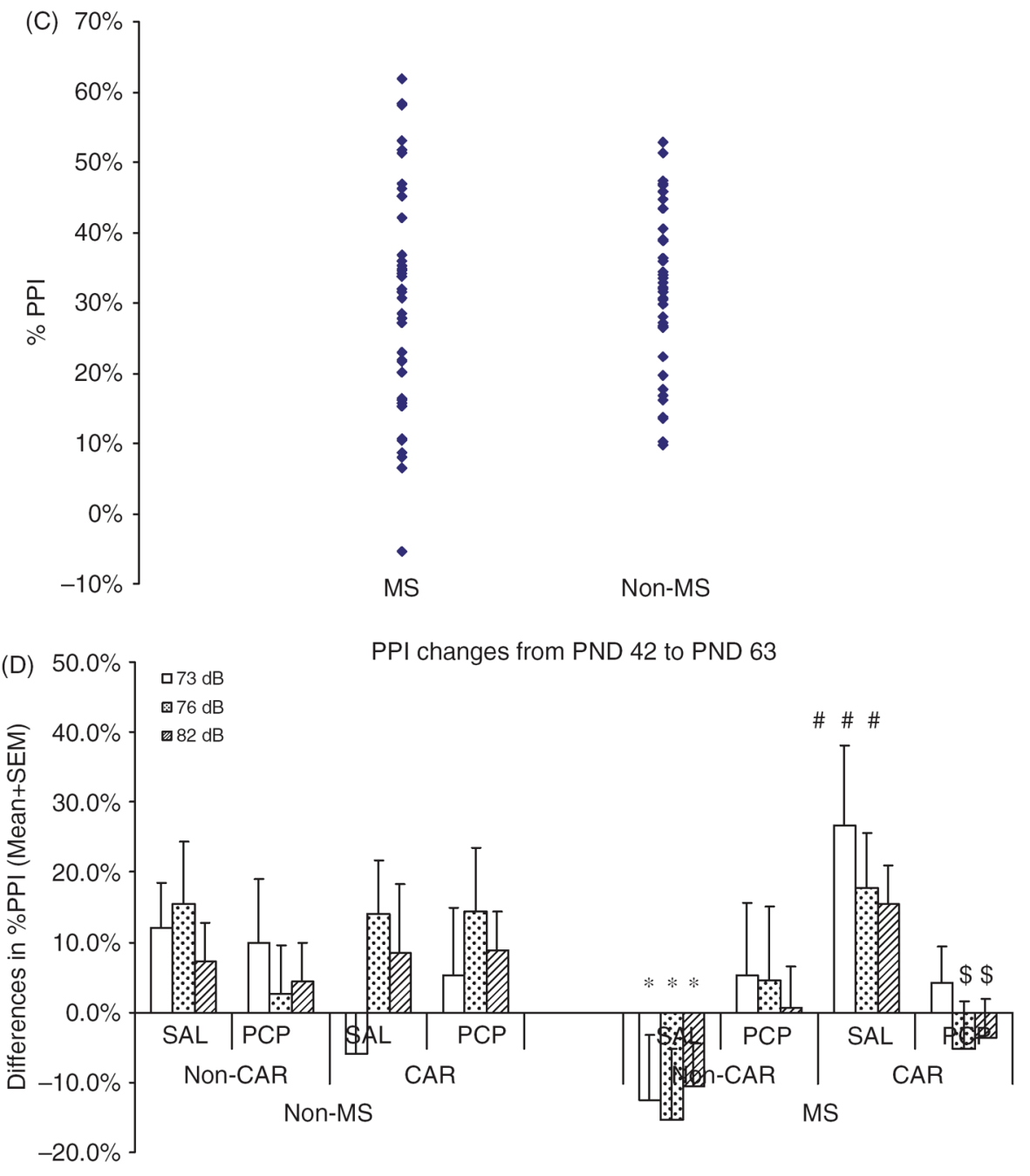

Figure 6. Continued.

adulthood (18-20 years old) (Tseng et al., 2009), and is the period when schizophrenia strikes most individuals with susceptible genes. As schizophrenia is usually "triggered" by psychosocial and environmental stress during the developmental period (Corcoran et al., 2001; Duncan et al., 1999), rats stressed and drugged during this period are likely to provide a better model of human conditions. Previous work has used pubertal PCP treatment alone or in combination with other manipulations to simulate human conditions that lead to schizophrenia. For example, Schwabe et al. (2006) showed that repeated PCP treatment on PND 42-48 reduced locomotor activity and disrupted some aspects of leaning and memory in the radial maze task. Our previous research also suggests that repeated phencyclidine treatment model is better than amphetamine models in mimicking antipsychotic effects as seen in the clinic (Sun et al., 2009). The present finding that repeated PCP treatment impaired avoidance learning in the MS adult rats is in line with this observation, suggesting that disrupting the glutamatergic N-methyl-D-aspartate (NMDA) receptor systems during the pubertal period can interact with prepubertal MS to exert a long-term effect on rat behaviors. The mechanism of action of PCP is complex (Jentsch and Roth, 1999). In addition to blocking NMDA receptor channels, PCP can enhance serotonergic, dopaminergic and glutamatergic neurotransmission in the nucleus accumbens and prefrontal cortex (Abekawa et al., 2007; Maurel-Remy et al., 1995; Millan et al., 1999), and repeated PCP treatment can also induce neurotoxic effects consisting of vacuole formation in pyramidal neurons in several corticolimbic brain regions including the posterior cingulate and retrosplenial cortices (Ellison, 1994; Ellison and Switzer, 1993; Olney et al., 1989, 1999), thus, one cannot exclude the possibility that the potentiated disruptive effect of repeated PCP treatment on PPI improvement in the maternally separated and avoidance trained rats is due to its actions on other neurotransmission systems (e.g. 5-HT, DA) and/or neurotoxicity. This issue needs further investigation, and the outcome of this line of research may shed light on the pathophysiology of schizophrenia. 
Finally, we comment on our choice of avoidance conditioning. We chose avoidance conditioning instead of other forms of stress as the "second hit" based on the following two considerations. First, avoidance conditioning allows us to examine the effects of early MS and PCP treatment on the ability of rats to learn under a stressful condition. Second, avoidance conditioning permits rats to have control over how much physical stress (i.e. footshock) they received. High avoidance rats (i.e. better learner with better stress coping strategy) received fewer shocks than low avoidance rats (i.e. slower learner with less-efficient stress coping strategy). These individual differences in avoidance performance are likely an important factor responsible for individual susceptibility to schizophrenia. As an example, we found that there was a significant linear correlation between the number of CS1 avoidances made on the first day and the \%PPI change at the $82 \mathrm{~dB}$ level in the MS rats treated with saline $(F(1,8)=12.072, p=0.008)$, suggesting that the high avoidance rats had better PPI improvement than low avoidance rats. Since we did not observe similar strong correlations with \%PPI changes at other levels, this conclusion needs further validation.

Taken together, the present study identified a complex three-way interaction among MS, avoidance conditioning and PCP treatment on the maturation-related development of sensorimotor gating ability, as measured by the improvement of PPI from the adolescence phase to adulthood phase. Together with other studies (Choy et al., 2009; Ellenbroek and Cools, 2002; Lehmann et al., 2000b), this study suggests that animal models with relevance to schizophrenia can be obtained by combining early developmental manipulations with later stress and/or drug treatments that disrupt the neurodevelopmental process. The "multiple-hit" model described here may be a useful tool for the study of the behavioral and neurobiological mechanisms underlying the effects of various developmental risk factors on the development of schizophrenia.

Acknowledgments - This study was funded in part by the Nebraska Tobacco Settlement Biomedical Research Development Funds to Dr Ming Li. Ms Jing Chen was supported by the Chinese Scholarship Council through its "Program of Governmental Graduate Student Scholarship" (PGGSS). We thank Wei He for his excellent technical support. We would like to thank Professor Ronald P. Hammer, Jr. $\mathrm{PhD}$ at the University of Arizona College of Medicine for his kind help on the prepulse inhibition task.

\section{References}

Abekawa T, Ito K, Koyama T (2007) Different effects of a single and repeated administration of clozapine on phencyclidine-induced hyperlocomotion and glutamate releases in the rat medial prefrontal cortex at short- and long-term withdrawal from this antipsychotic. Naunyn Schmiedebergs Arch Pharmacol 375: 261-271.

Anda RF, Felitti VJ, Bremner JD, et al. (2006) The enduring effects of abuse and related adverse experiences in childhood: a convergence of evidence from neurobiology and epidemiology. Eur Arch Psychiatry Clin Neurosci 256: 174-186.
Andersen JD, Pouzet B (2004) Spatial memory deficits induced by perinatal treatment of rats with PCP and reversal effect of Dserine. Neuropsychopharmacology 29: 1080-1090.

Anglin DM, Cohen PR, Chen H (2008) Duration of early maternal separation and prediction of schizotypal symptoms from early adolescence to midlife. Schizophr Res 103: 143-150.

Antoniadis EA, McDonald RJ (1999) Discriminative fear conditioning to context expressed by multiple measures of fear in the rat. Behav Brain Res 101: 1-13.

Bayer TA, Falkai P, Maier W (1999) Genetic and non-genetic vulnerability factors in schizophrenia: the basis of the "two hit hypothesis". J Psychiatr Res 33: 543-548.

Bifulco A, Brown GW, Adler Z (1991) Early sexual abuse and clinical depression in adult life. Br J Psychiatry 159: 115-122.

Braff DL, Geyer MA, Light GA, et al. (2001) Impact of prepulse characteristics on the detection of sensorimotor gating deficits in schizophrenia. Schizophr Res 49: 171-178.

Carpenter WT, Jr, Buchanan RW (1994) Schizophrenia. N Engl J Med 330: 681-690.

Chapman RH, Stern JM (1979) Failure of severe maternal stress or ACTH during pregnancy to affect emotionality of male rat offspring: Implications of litter effects for prenatal studies. Dev Psychobiol 12: 255-267.

Choy KH, de Visser Y, Nichols NR, van den Buuse M (2008) Combined neonatal stress and young-adult glucocorticoid stimulation in rats reduce BDNF expression in hippocampus: Effects on learning and memory. Hippocampus 18: 655-667.

Choy KH, de Visser YP, van den Buuse M (2009) The effect of "two hit" neonatal and young-adult stress on dopaminergic modulation of prepulse inhibition and dopamine receptor density. Br J Pharmacol 156: 388-396.

Choy KH, van den Buuse M (2008) Attenuated disruption of prepulse inhibition by dopaminergic stimulation after maternal deprivation and adolescent corticosterone treatment in rats. Eur Neuropsychopharmacol 18: 1-13.

Cirulli F, Berry A, Alleva E (2003) Early disruption of the motherinfant relationship: Effects on brain plasticity and implications for psychopathology. Neurosci Biobehav Rev 27: 73-82.

Corcoran C, Gallitano A, Leitman D, Malaspina D (2001) The neurobiology of the stress cascade and its potential relevance for schizophrenia. J Psychiatr Pract 7: 3-14.

Duncan GE, Sheitman BB, Lieberman JA (1999) An integrated view of pathophysiological models of schizophrenia. Brain Res Brain Res Rev 29: 250-264.

Ellenbroek BA, Cools AR (2002) Early maternal deprivation and prepulse inhibition: The role of the postdeprivation environment. Pharmacol Biochem Behav 73: 177-184.

Ellenbroek BA, de Bruin NM, van Den Kroonenburg PT, van Luijtelaar EL, Cools AR (2004) The effects of early maternal deprivation on auditory information processing in adult Wistar rats. Biol Psychiatry 55: 701-707.

Ellenbroek BA, van den Kroonenberg PT, Cools AR (1998) The effects of an early stressful life event on sensorimotor gating in adult rats. Schizophr Res 30: 251-260.

Ellison G (1994) Competitive and non-competitive NMDA antagonists induce similar limbic degeneration. Neuroreport 5: 2688-2692. 
Ellison G, Switzer RC, III (1993) Dissimilar patterns of degeneration in brain following four different addictive stimulants. Neuroreport 5: 17-20.

Fitzgerald M, Anand K (1993) The developmental neuroanatomy and neurophysiology of pain. In: Schechter N, Berde C, \& Yaster M (eds.) Pain Management in Infants, Children and Adolescents. Baltimore, MD: Williams \& Williams, 11-32.

Francis DD, Diorio J, Plotsky PM, Meaney MJ (2002) Environmental enrichment reverses the effects of maternal separation on stress reactivity. J Neurosci 22: 7840-7843.

Holmes A, le Guisquet AM, Vogel E, Millstein RA, Leman S, Belzung C (2005) Early life genetic, epigenetic and environmental factors shaping emotionality in rodents. Neurosci Biobehav Rev 29: 1335-1346.

Huot RL, Thrivikraman KV, Meaney MJ, Plotsky PM (2001) Development of adult ethanol preference and anxiety as a consequence of neonatal maternal separation in Long Evans rats and reversal with antidepressant treatment. Psychopharmacology (Berl) 158: 366-373.

Iijima M, Chaki S (2005) Separation-induced ultrasonic vocalization in rat pups: Further pharmacological characterization. Pharmacol Biochem Behav 82: 652-657.

Javitt DC, Zukin SR (1991) Recent advances in the phencyclidine model of schizophrenia. Am J Psychiatry 148: 1301-1308.

Jentsch JD, Roth RH (1999) The neuropsychopharmacology of phencyclidine: From NMDA receptor hypofunction to the dopamine hypothesis of schizophrenia. Neuropsychopharmacology 20: 201-225.

Kilts CD (2001) The changing roles and targets for animal models of schizophrenia. Biol Psychiatry 50: 845-855.

Le Pen G, Grottick AJ, Higgins GA, Moreau JL (2003) Phencyclidine exacerbates attentional deficits in a neurodevelopmental rat model of schizophrenia. Neuropsychopharmacology 28: 1799-1809.

Lehmann J, Pryce CR, Feldon J (2000a) Lack of effect of an early stressful life event on sensorimotor gating in adult rats. Schizophr Res 41: 365-371.

Lehmann J, Stohr T, Feldon J (2000b) Long-term effects of prenatal stress experiences and postnatal maternal separation on emotionality and attentional processes. Behav Brain Res 107: 133-144.

Lewis DA, Lieberman JA (2000) Catching up on schizophrenia: Natural history and neurobiology. Neuron 28: 325-334.

Li M, He W, Mead A (2009a) Olanzapine and risperidone disrupt conditioned avoidance responding in phencyclidine-pretreated or amphetamine-pretreated rats by selectively weakening motivational salience of conditioned stimulus. Behav Pharmacol 20: 84-98.

Li M, He W, Munro R (2008) Amphetamine selectively enhances avoidance responding to a less salient stimulus in rats. $J \mathrm{Neu-}$ ral Transm 115: 773-776.

Li M, Mead A, Bevins RA (2009b) Individual differences in responses to nicotine: Tracking changes from adolescence to adulthood. Acta Pharmacol Sin 30: 868-878.

Li M, Parkes J, Fletcher PJ, Kapur S (2004) Evaluation of the motor initiation hypothesis of APD-induced conditioned avoidance decreases. Pharmacol Biochem Behav 78: 811-819.
Lipska BK, Weinberger DR (2002) A neurodevelopmental model of schizophrenia: Neonatal disconnection of the hippocampus. Neurotox Res 4: 469-475.

Liu D, Caldji C, Sharma S, Plotsky PM, Meaney MJ (2000) Influence of neonatal rearing conditions on stress-induced adrenocorticotropin responses and norepinepherine release in the hypothalamic paraventricular nucleus. J Neuroendocrinol 12: 5-12.

Lupien SJ, McEwen BS, Gunnar MR, Heim C (2009) Effects of stress throughout the lifespan on the brain, behaviour and cognition. Nat Rev Neurosci 10: 434-445.

Machon RA, Mednick SA, Schulsinger F (1987) Seasonality, birth complications and schizophrenia in a high risk sample. $\mathrm{Br} \mathrm{J}$ Psychiatry 151: 122-124.

Mackinnon A, Henderson AS, Andrews G (1993) Parental “affectionless control" as an antecedent to adult depression: a risk factor refined. Psychol Med 23: 135-141.

Marenco S, Weinberger DR (2000) The neurodevelopmental hypothesis of schizophrenia: Following a trail of evidence from cradle to grave. Dev Psychopathol 12: 501-527.

Maurel-Remy S, Bervoets K, Millan MJ (1995) Blockade of phencyclidine-induced hyperlocomotion by clozapine and MDL 100,907 in rats reflects antagonism of 5-HT2A receptors. Eur J Pharmacol 280: R9-R11.

Maynard TM, Sikich L, Lieberman JA, LaMantia AS (2001) Neural development, cell-cell signaling, and the "two-hit" hypothesis of schizophrenia. Schizophr Bull 27: 457-476.

Mead A, Li M, and Kapur S (2008) Clozapine and olanzapine exhibit an intrinsic anxiolytic property in two conditioned fear paradigms: Contrast with haloperidol and chlordiazepoxide. Pharmacol Biochem Behav 90: 551-562.

Mednick SA, Machon RA, Huttunen MO, Bonett D (1988) Adult schizophrenia following prenatal exposure to an influenza epidemic. Arch Gen Psychiatry 45: 189-192.

Millan MJ, Brocco M, Gobert A, et al. (1999) Contrasting mechanisms of action and sensitivity to antipsychotics of phencyclidine versus amphetamine: Importance of nucleus accumbens 5-HT2A sites for PCP-induced locomotion in the rat. Eur J Neurosci 11: 4419-4432.

Millstein RA, Ralph RJ, Yang RJ, Holmes A (2006) Effects of repeated maternal separation on prepulse inhibition of startle across inbred mouse strains. Genes Brain Behav 5: 346-354.

Mowrer OH, Lamoreaux RR (1946) Fear as an intervening variable in avoidance conditioning. J Comput Psychol 39: 29-50.

Muller JM, Brunelli SA, Moore H, Myers MM, Shair HN (2005) Maternally modulated infant separation responses are regulated by D2-family dopamine receptors. Behav Neurosci 119: 1384-1388.

Olivier B, Molewijk E, van Oorschot R, van der Heyden J, Ronken E, Mos J (1998) Rat pup ultrasonic vocalization: effects of benzodiazepine receptor ligands. Eur J Pharmacol 358: 117-128.

Olney JW, Labruyere J, Price MT (1989) Pathological changes induced in cerebrocortical neurons by phencyclidine and related drugs. Science 244: 1360-1362.

Olney JW, Newcomer JW, Farber NB (1999) NMDA receptor hypofunction model of schizophrenia. J Psychiatr Res 33: 523-533.

Pantelis C, Yucel M, Wood SJ, McGorry PD, Velakoulis D (2003) Early and late neurodevelopmental disturbances in schizo- 
phrenia and their functional consequences. Aust N Z J Psychiatry 37: 399-406.

Pryce CR, Bettschen D, Nanz-Bahr NI, Feldon J (2003) Comparison of the effects of early handling and early deprivation on conditioned stimulus, context, and spatial learning and memory in adult rats. Behav Neurosci 117: 883-893.

Rees SL, Steiner M, Fleming AS (2006) Early deprivation, but not maternal separation, attenuates rise in corticosterone levels after exposure to a novel environment in both juvenile and adult female rats. Behav Brain Res 175: 383-391.

Rescorla RA, Solomon RL (1967) Two-process learning theory: Relationships between Pavlovian conditioning and instrumental learning. Psychol Rev 74: 151-182.

Robinson TE, Becker JB (1986) Enduring changes in brain and behavior produced by chronic amphetamine administration: A review and evaluation of animal models of amphetamine psychosis. Brain Res 396: 157-198.

Rosenfeld P, Wetmore JB, Levine S (1992) Effects of repeated maternal separations on the adrenocortical response to stress of preweanling rats. Physiol Behav 52: 787-791.

Schwabe K, Klein S, Koch M (2006) Behavioural effects of neonatal lesions of the medial prefrontal cortex and subchronic pubertal treatment with phencyclidine of adult rats. Behav Brain Res 168: 150-160.

Shair HN (2007) Acquisition and expression of a socially mediated separation response. Behav Brain Res 182: 180-192.

Siris SG (1994) Schizophrenia. In: Hirsch SR, Weinberger DR (eds) Schizophrenia: Exploring the Spectrum of Psychosis. Oxford: Blackwell, 128-145.

Spear LP (2000) The adolescent brain and age-related behavioral manifestations. Neurosci Biobehav Rev 24: 417-463.

Sullivan R, Wilson DA, Feldon J, et al. (2006) The International Society for Developmental Psychobiology annual meeting symposium: Impact of early life experiences on brain and behavioral development. Dev Psychobiol 48: 583-602.

Sun T, Hu G, Li M (2009) Repeated antipsychotic treatment progressively potentiates inhibition on phencyclidine-induced hyperlocomotion, but attenuates inhibition on amphetamineinduced hyperlocomotion: Relevance to animal models of antipsychotic drugs. Eur J Pharmacol 602: 334-342.

Swerdlow NR, Weber M, Qu Y, Light GA, Braff DL (2008) Realistic expectations of prepulse inhibition in translational models for schizophrenia research. Psychopharmacology (Berl) 199: 331-388.

Tseng KY, Chambers RA, Lipska BK (2009) The neonatal ventral hippocampal lesion as a heuristic neurodevelopmental model of schizophrenia. Behav Brain Res 204: 295-305.

Van den Buuse M, Garner B, Koch M (2003) Neurodevelopmental animal models of schizophrenia: Effects on prepulse inhibition. Curr Mol Med 3: 459-471.

Wang C, McInnis J, Ross-SanchezM, Shinnick-Gallagher P, Wiley JL, Johnson KM (2001) Long-term behavioral and neurodegenerative effects of perinatal phencyclidine administration: Implications for schizophrenia. Neuroscience 107: 535-550.

Weinberger DR (1996) On the plausibility of "the neurodevelopmental hypothesis" of schizophrenia. Neuropsychopharmacology 14: 1S-11S

Weiss IC, Feldon J (2001) Environmental animal models for sensorimotor gating deficiencies in schizophrenia: A review. Psychopharmacology (Berl) 156: 305-326.

Weiss IC, Domeney AM, Moreau JL, Russig H, Feldon J (2001) Dissociation between the effects of pre-weaning and/or postweaning social isolation on prepulse inhibition and latent inhibition in adult Sprague-Dawley rats. Behav Brain Res 121: 207-218.

Wigger A, Neumann ID (1999) Periodic maternal deprivation induces gender-dependent alterations in behavioral and neuroendocrine responses to emotional stress in adult rats. Physiol Behav 66: 293-302.

Wilkinson LS, Killcross SS, Humby T, Hall FS, Geyer MA, Robbins TW (1994) Social isolation in the rat produces developmentally specific deficits in prepulse inhibition of the acoustic startle response without disrupting latent inhibition. Neuropsychopharmacology 10: 61-72. 